\title{
The Importance of Bottom-Up Approaches to International Cooperation in Ocean Science THE IRON STORY
}

\author{
By Edward R. Urban Jr., Andrew R. Bowie, Philip W. Boyd, Kristen N. Buck, Maeve C. Lohan, Sylvia G. Sander, \\ Reiner Schlitzer, Alessandro Tagliabue, and David Turner
}

\begin{abstract}
In the past decade, several international efforts developed to address urgent societal issues have been identified through, for example, the United Nations 2030 Agenda for Sustainable Development and its associated 17 Sustainable Development Goals and the United Nations Decade of Ocean Science for Sustainable Development (2021-2030). These worthy efforts will bring ocean science research to bear on problems that need attention in the short term. Yet, there is also a continuing need at the international level to support fundamental ocean science and solve methodological issues over the long term. While knowledge needs to be created before it can be applied, national and international science strategy documents often do not mention the need to maintain the health of the basic science enterprise. We argue that international organizations designed to create knowledge must be maintained and strengthened to inform decisions on how to allocate funding for generating knowledge about the ocean versus solving ocean problems. We use the ocean iron cycle as an example of the benefits of using such a "bottom-up" approach to knowledge generation.
\end{abstract}

\section{INTRODUCTION}

The founders of modern oceanography understood the global nature of the ocean system and concluded that ocean science research would be strengthened by collaborative efforts among ocean scientists from different nations. The 1957-1958 International Geophysical Year (IGY) highlighted what could be accomplished through international approaches to ocean science (Wolff, 2010). The International Council of Scientific Unions (ICSU) formed a Comité Special de l'Année Géophysique Internationale (CSAGI) for the IGY (Wolff, 2010). At this time, CSAGI was the only ICSU interdisciplinary committee; the only ICSU body related to ocean science was the International Association of Physical Oceanography (IAPO) of the International Union of Geodesy

'SCOR's name was later changed to Scientific Committee on Oceanic Research. ocean research and solve methodological problems that hinder research. SCOR was formed by some of the same scientists who were leaders of CSAGI. Since its formation, SCOR has provided means to enlist the ideas, enthusiasm, and energy of scientists to increase knowledge of the ocean-knowledge that, in turn, is useful for addressing societal issues. SCOR's success in promoting the importance of securing fundamental knowledge about the ocean offers clues to factors that are important for keeping such knowledge generation a healthy enterprise.

SCOR is based on a system of national SCOR committees. These committees pay dues to maintain the SCOR Secretariat and to support working groups and other SCOR activities. With this financial base, SCOR provides administrative support to its working groups and projects at no cost, as a service to the international ocean science community. Another key function of national SCOR committees is to nominate and elect officers for the SCOR Executive Committee, which is
DEDICATION. This article is dedicated to the late Keith Hunter, who passed away on October 24, 2018. Keith was a complex and wonderful person, a full-blooded researcher and brilliant scientist, and also the most down-to-earth person-digging up some potatoes in his garden or sitting down at home with a glass of good whiskey looking over the sea. Keith was one of the first chemical oceanographers to embrace John Martin's hypothesis that iron is a limiting nutrient in many parts of the global surface ocean. In 1996, Keith and David Turner initiated and then co-chaired the very first of SCOR's iron-related working groups, WG 109 on the Biogeochemistry of Iron in Seawater. Keith was an inspiring supervisor and mentor, a staunch supporter of great research, and an outstanding scientist, as reflected in his more than 150 publications, software innovations, and receipt of numerous science awards and prizes. He will live on in our memories, and the ideas he inspired in many of us will be his legacy. 

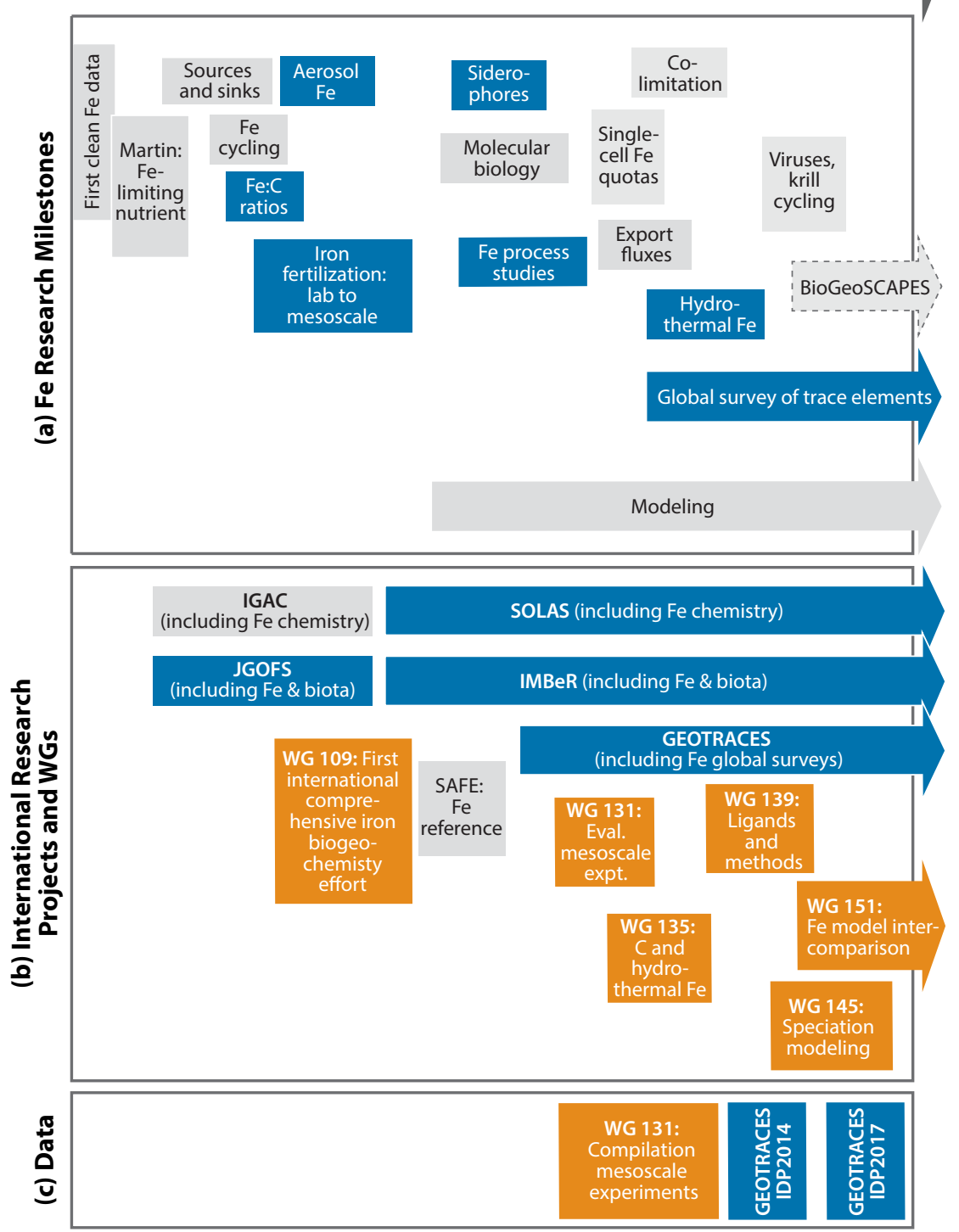

FIGURE 1. Timeline of SCOR contributions to advancing understanding of iron chemistry in seawater. Activities sponsored by SCOR are in blue. SCOR-sponsored working groups are in orange. Projects not supported directly by SCOR are gray. (a) Milestones reached in relevant global research projects and topics. BioGeoSCAPES (https://www.biogeoscapes. org/) is represented with a dashed arrow, as it is a developing project that could contribute new understanding of the role of organisms in the global iron cycle. (b) Major developments in advancing understanding of iron chemistry in the ocean, including contributions from SCOR-sponsored research projects and SCOR Working Groups. (c) SCOR-sponsored contributions to data.

GEOTRACES = an international study of marine biogeochemical cycles of trace elements and their isotopes

IDP = Intermediate Data Product

IGAC = International Global Atmospheric Chemistry project (Future Earth)

IMBeR = Integrated Marine Biosphere Research Project (SCOR and Future Earth)

$\mathrm{SAFe}=$ Sampling and Analysis of Iron intercomparison exercise

SOLAS = Surface Ocean-Lower Atmosphere Study (SCOR, Future Earth, World Climate

Research Programme, and international Commission on Atmospheric Chemistry and Atmospheric Pollution)

WG 109 = Biogeochemistry of Iron in Seawater

WG 131 = The Legacy of in situ Iron Enrichment: Data Compilation and Modeling

WG 135 = Hydrothermal Energy Transfer and its Impact on the Ocean Carbon Cycles

WG 139 = Organic Ligands - A Key Control on Trace Metal Biogeochemistry in the Ocean WG 145 = Modelling Chemical Speciation in Seawater to Meet 21st Century Needs

(MARCHEMSPEC)

WG 151 = Iron Model Intercomparison Project (FeMIP) responsible for all SCOR activities.

SCOR's main strength, and what makes it unique, is that it empowers individual scientists to gather together international groups to develop new research projects, form working groups, and manage projects related to the infrastructure of specific areas of ocean science. Most national funding agencies only support activities of scientists from or within their nations. SCOR's funding has no national limitations, its activities range from very disciplinary to multidisciplinary, and they incorporate all areas of ocean science, from coastal waters to the deep sea, from research to observations to modeling and synthesis. No other international ocean science organization provides these broad opportunities to the ocean science community.

SCOR has helped advance many areas of ocean science via working groups and research projects initiated by the scientific community, including air-sea gas and material transfers; the equation of state of seawater; ocean carbon, including acidification; harmful algal blooms; pelagic fish populations and climate change; methods for phytoplankton and zooplankton identification and analysis; paleoceanography; trace elements and isotopes in the ocean, particularly iron; and many others (see https://scor-int.org/scor/achievements/). SCOR gave early attention to many topics that are now the central concerns of other organizations.

SCOR's contributions to understanding the global iron cycle demonstrate the importance of "bottom-up" approaches to advancing science. SCOR activities have contributed to improved understanding of iron chemistry in seawater, iron effects on biota, and iron biogeochemistry. They have helped solve methodological issues related to measuring and modeling iron in the ocean and supported the generation and archiving of ocean iron data. Like many scientific advances, our understanding of iron biogeochemistry in the ocean evolved not only through research and development of techniques in individual laboratories but also through collaborations between international groups of scientists who contributed their experience, time, and other resources. Figure 1 places SCORsupported work in the context of other activities in the field. SCOR-supported science has made possible revisions in the conceptual view of the marine iron cycle from WG 109 to the present. 


\section{SCOR WORKING GROUP CONTRIBUTIONS TO IRON STUDIES}

SCOR calls for proposals for new working groups annually and typically approves two new groups each year. Working groups advance specific areas of ocean science over a three- to fouryear period by identifying priority science, coordinating international intercalibrations, identifying best practices, and working on obstacles that hinder their area of ocean science. New working group proposals are reviewed by national SCOR committees, which provide a significant portion of the funding for these groups, as well as by partner organizations and any interested scientists. To date, SCOR has contributed to advancing understanding of iron through six working groups $(109,131,135,139,145$, and 151-see definitions in Figure 1 caption). Several of the later working groups are built on the foundations provided by earlier groups, and many contributed to the research project GEOTRACES, described in the next section.

SCOR activity in relation to iron in the ocean started in 1996 with SCOR/ International Union of Pure and Applied
Chemistry (IUPAC) Working Group (WG) 109. The purpose of WG 109 was to document our understanding of iron chemistry in the ocean in the mid1990s and to identify priorities for future research. This group was formed following the community's recognition of iron as a key element in controlling ocean productivity (Martin and Fitzwater, 1988). The work of WG 109 was published in a book entitled The Biogeochemistry of Iron in Seawater (Turner and Hunter, 2001). WG 109 also led to an intercomparison of measurements of iron in seawater in a project called IRONAGES that involved 24 laboratories using seven different analytical techniques (Bowie et al., 2006). This intercomparison exercise found that although measurement capabilities had improved significantly in relation to previous intercomparisons (Bewers et al., 1981; Landing et al., 1995), the range of results was still unacceptably large among different laboratories.

SCOR WG 131, established in 2007, compiled data from nine of the 13 largescale iron fertilization experiments conducted between 1993 and 2009 (Boyd et al., 2012; Figure 2) in order to make the data available for analyses of simi- larities and differences among the systems that could help explain the different ecosystem responses to iron additions in various regions.

SCOR/InterRidge WG 135, formed in 2008, contributed to understanding and modeling of iron released from hydrothermal systems and its relation to organic carbon (German et al., 2015) by modeling data from the East Pacific Rise and applying it to known global hydrothermal venting.

SCOR Working Group 139 was convened in 2011 to bring together trace metal biogeochemists, organic geochemists, and biogeochemical modelers to improve our understanding of how metalbinding organic ligands affect marine biogeochemical cycles, including for iron. Outcomes of WG 139 included the publication of more than 50 research articles across two special journal issues, in Marine Chemistry (Lohan et al., 2015) and Frontiers in Marine Science (Buck et al., 2017).

SCOR WG 145 was established in 2014 in recognition of the need for freely available software to calculate chemical speciation of elements in seawater. This group has documented the currently
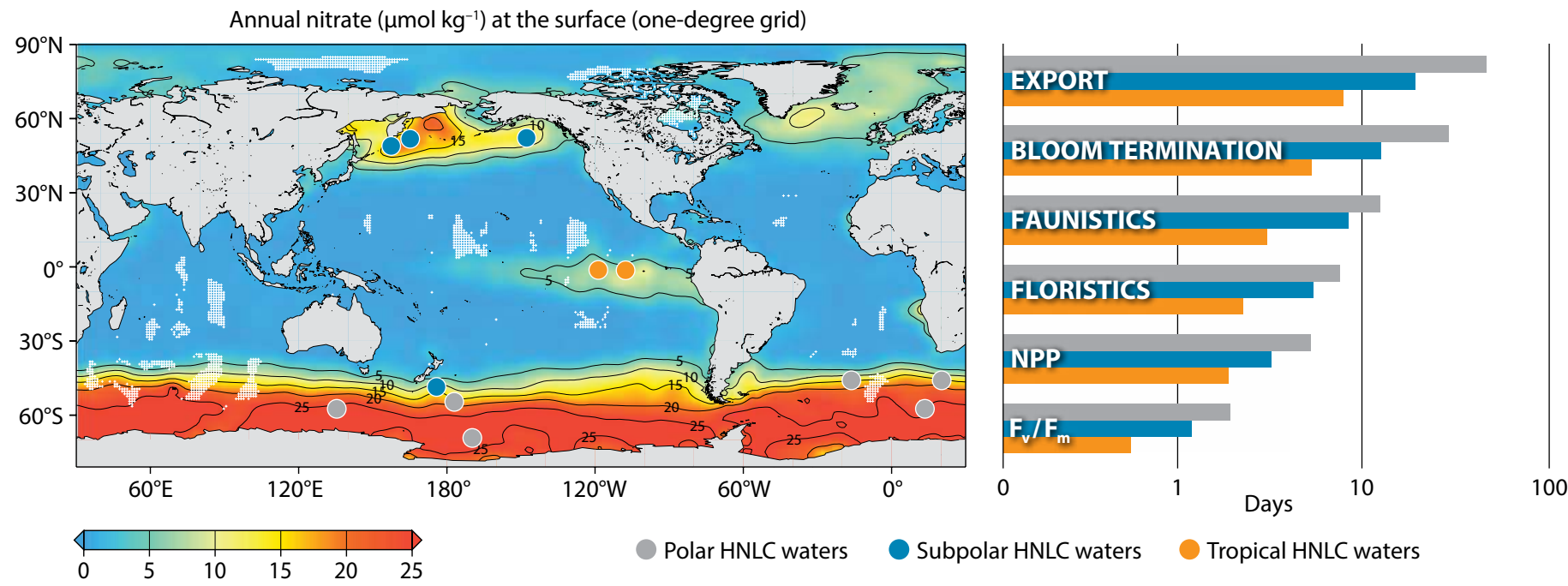

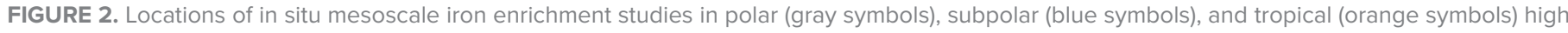

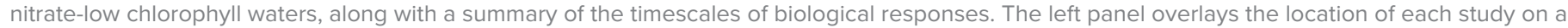

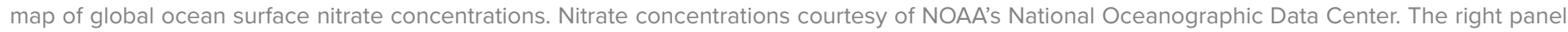

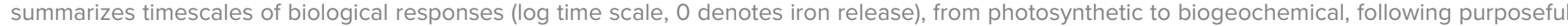

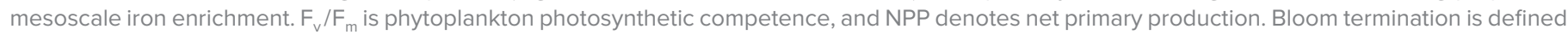

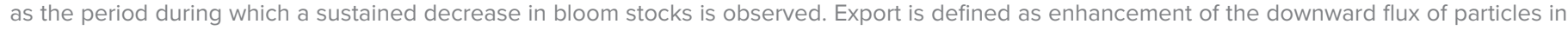

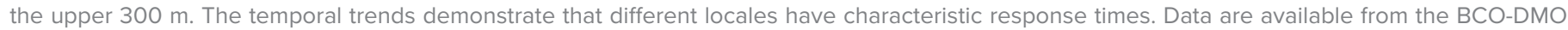
relational database (https://www.bco-dmo.org/program/2017). Figure modified from Boyd et al. (2012) 
available seawater speciation models that use Pitzer equations (Pitzer, 1991; Turner et al., 2016), which are considered to be the current state of the art for chemical speciation calculations in complex media such as seawater. WG 145 is developing web-based software to make it possible to determine the speciation of trace metals, carbonate ions, and other components of seawater.

SCOR WG 151 is extending the work of Tagliabue et al. (2016), which showed that global biogeochemistry models are not adequate or consistent in how they represent iron and processes involving iron. This working group aims to support the improved understanding of the role of iron in shaping large-scale biogeochemical cycles in global ocean models and their projected responses to climate change.

\section{SCOR-SUPPORTED RESEARCH PROJECTS- GEOTRACES EXAMPLE}

SCOR also provides mechanisms for groups of scientists to self-assemble around science topics that would benefit from a coordinated international approach; individual research projects are then funded by national funding agencies. SCOR convenes open science meetings on the designated topics to define priority research questions, forms planning committees using this input to create project science plans, and assembles

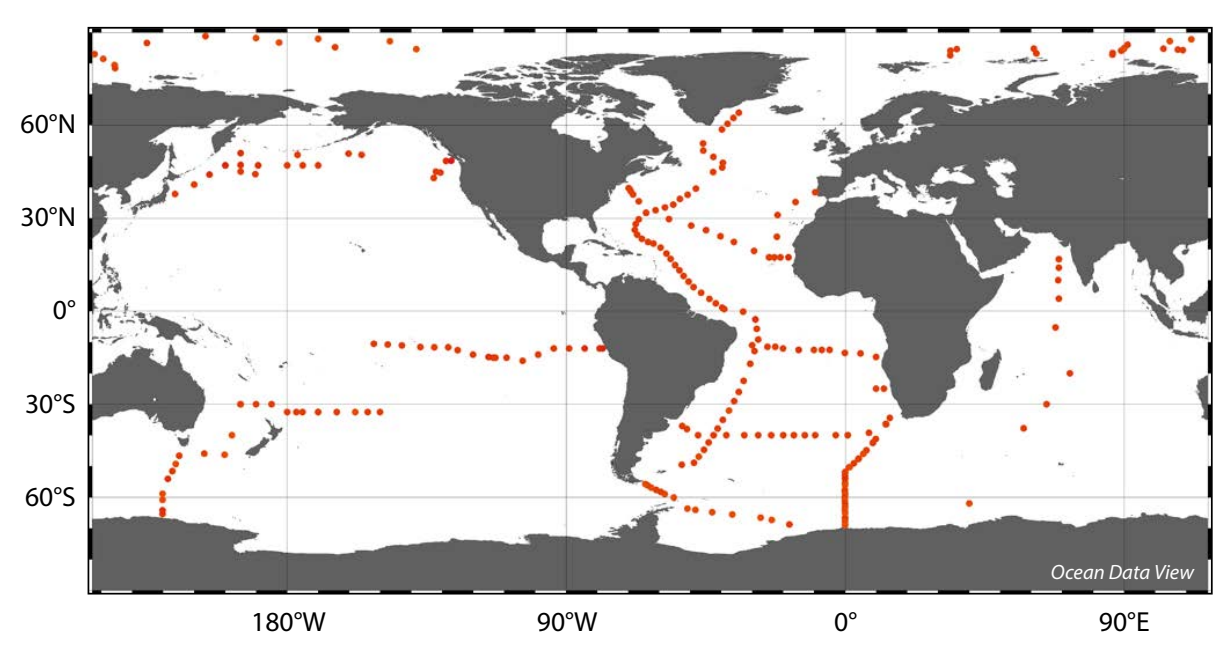

FIGURE 3. Locations of GEOTRACES stations with iron data, from the surface to the seafloor (IDP2017; Schlitzer et al., 2018), including data through 2016. Figure courtesy of Reiner Schlitzer (AWI) scientific steering committees to manage the projects. Besides national support for project coordination, Australia, Canada, China, France, Germany, Poland, and the UK currently support international project offices and regional offices for SCOR research and other projects; these offices are vital for success of SCOR projects. SCOR currently supports five international research projects, and drawing on its long history in ocean science, helps ensure the transfer of lessons learned from completed projects to new projects.

GEOTRACES (http://www.geotraces. org/) provides an excellent example of how SCOR involvement can help assure project success. Based on international community and national funding agency interest in a new large-scale research project on trace elements and isotopes in the ocean, in 2004 SCOR supported the formation of a planning committee for a new project called GEOTRACES. (GEOTRACES had already held its own open science meeting with support from the US National Science Foundation, but SCOR helped support the planning committee to create a science plan based on the outputs from the open science meeting.) SCOR accepted GEOTRACES as one of its large-scale research projects in 2005 and worked with the project leaders to develop an international Scientific Steering Committee (SSC) and terms of reference for the program. For the dura-

tion of the project, SCOR approved appointments of members of the SSC, who were responsible for the project's scientific direction, as well as any changes in the terms of reference.

Before an International Project Office (IPO) is established, and at no cost to the project or the national funding agencies, SCOR staff offer services that are normally provided by an IPO (e.g., administrative support, advice on meeting planning and logistics, communications), albeit at a reduced level. Since GEOTRACE's IPO was formed, SCOR has handled many of the financial functions for the project, including fundraising for project meetings and offices, and has handled reimbursements for project meetings. SCOR has also provided advice on project strategies for communication, outreach, and capacity development. SCOR reviews each of its projects every five years; GEOTRACES has just received a very favorable review from an independent review committee. Given SCOR's international reputation, research projects gain an intangible benefit from being SCOR-supported projects. There are no other international mechanisms to gather national support for planning and coordination of international ocean research projects.

GEOTRACES is the only SCOR project that is compiling a global data set. This data set is managed by a GEOTRACES Data Management Committee, which works with SCOR-supported staff (with funds from NSF and other sources) at the British Oceanographic Data Centre. The GEOTRACES project has vastly expanded the amount of iron data available in all ocean basins, from the surface to the seafloor (Lam and Anderson, 2018), made these data available in a relational database (see https://www. bodc.ac.uk/geotraces/data/idp2017/), and visually represented the data in the eGEOTRACES atlas (see http://www. egeotraces.org/). A total of 12,050 iron measurements are included in the 2017 GEOTRACES Intermediate Data Product (IDP; Schlitzer et al., 2018) (Figure 3). All iron data in the GEOTRACES IDPs have 
been thoroughly scrutinized through intercalibration and the analysis of reference samples, so that only high-quality measurements are included (Bowie and Tagliabue, 2018). Since 2016, further GEOTRACES section cruises and process studies have been carried out in the Atlantic, Indian, Pacific, and Southern Oceans, which will result in the addition of considerable iron data in the 2021 GEOTRACES IDP.

\section{CONCLUSIONS}

SCOR, with its unique mandate to bring the international ocean science community together to formulate new ideas, has contributed to furthering our understanding of the ocean for more than 60 years. Bottom-up identification of important ocean science issues works because the community is the best arbiter of what issues need focused attention, and SCOR provides the mechanisms and funding to empower the community to implement its ideas. This approach has made it possible for segments of the ocean science community to self-organize to address issues that may not reach the level of "grand challenges," but that need to be handled by some international organization to produce results that are accepted worldwide. The review process for SCOR working group proposals ensures that only the best ideas, those that are amenable to progress using SCOR mechanisms, are implemented.

The SCOR Executive Committee did not predetermine in 1996 to make iron in the ocean a major theme of SCOR work for the next 24 years, but the set of activities approved and funded by SCOR have done just that. The spacing of these activities over a 24-year period allowed each activity to build on the successes of previous activities and reflected development in underlying science being conducted by the global community. It is likely that SCOR will continue to support working groups on aspects of iron in the ocean as long as scientific and methodological issues require international attention. This example extends across many other topics to which SCOR has contributed. If SCOR did not exist, there is no other mechanism to combine financial resources from 31 countries to address important ocean science issues identified by the international community. [

\section{REFERENCES}

Bewers, J.M., J.A. Dalziel, P.A. Yeats, and J.L. Barron. 1981. An intercalibration for trace metals in seawater. Marine Chemistry 10:173-193, https://doi.org/ 10.1016/0304-4203(81)90040-2.

Bowie, A.R., E.P. Achterberg, P.L. Croot,

H.J.W. de Baar, P. Laan, J.W. Moffett, S. Ussher, and P.J. Worsfold. 2006. A community-wide intercomparison exercise for the determination of dissolved iron in seawater. Marine Chemistry 98:81-99, https://doi.org/10.1016/j.marchem.2005.07.002.

Bowie, A., and A. Tagliabue. 2018. GEOTRACES data products: Standardising and linking ocean trace element and isotope data at a global scale. Elements 14:436-437, https://doi.org/10.2138/ gselements.14.6.436.

Boyd, P.W., D.C.E. Bakker, and C. Chandler. 2012. A new database to explore the findings from large-scale ocean iron enrichment experiments. Oceanography 25(4):64-71, https://doi.org/ 10.5670/oceanog.2012.104.

Buck, K.N., M.C. Lohan, S.G. Sander, C. Hassler, and I. Pizeta. 2017. Editorial: Organic ligands-A key control on trace metal biogeochemistry in the ocean. Frontiers in Marine Science, https://doi.org/ 10.3389/fmars.2017.00313.

German, C.R., L.L. Legendre, S.G. Sander, N. Niquil, G.W. Luther, L. Bharati, X. Han, and N. Le Bris. 2015. Hydrothermal Fe cycling and deep ocean organic carbon scavenging: Model-based evidence for significant POC supply to seafloor sediments. Earth and Planetary Science Letters 419:143-153, https://doi.org/10.1016/j.epsl.2015.03.012.

Lam, P.J., and R.F. Anderson. 2018. GEOTRACES: The marine biogeochemical cycle of trace elements and their isotopes. Elements 14:377-378.

Landing, W.M., G.A. Cutter, J.A. Dalziel, A.R. Flegal, R.T. Powell, D. Schmidt, A. Shiller, P.J. Statham, S. Westerlund, and J. Resing, 1995. Analytical intercomparison results from the 1990 Intergovernmental Oceanographic Commission open-ocean baseline survey for trace metalsAtlantic Ocean. Marine Chemistry 49:253-265, https://doi.org/10.1016/0304-4203(95)00016-K.

Lohan, M.C., K.N. Buck, and S.G. Sander. 2015 Organic ligands-A key control on trace metal biogeochemistry in the oceans. Marine Chemistry 173:1-2, https://doi.org/10.1016/ j.marchem.2015.03.017.

Martin, J.H., and S.E. Fitzwater. 1988. Iron-deficiency limits phytoplankton growth in the Northeast Pacific Subarctic. Nature 331:341-343, https://doi.org/ 10.1038/331341a0.

Pitzer, K.S. 1991. Ion interaction approach: Theory and data correlation. Pp. 75-153 in Activity Coefficients in Electrolyte Solutions. K.S. Pitzer, ed., CRC Press, Boca Raton, Florida.

Schlitzer, R., R.F. Anderson, E. Masferrer Dodas, M. Lohan, W. Geibert, A. Tagliabue, A. Bowie, C. Jeandel, M.T. Maldonado, W.M. Landing, and others. 2018. The GEOTRACES Intermediate Data Product 2017. Chemical Geology 493:210223, https://doi.org/10.1016/J.CHEMGEO.2018.05.040.

Tagliabue., A., O. Aumont, R. DeAth, J.P. Dunne, S. Dutkiewicz, E. Galbraith, K. Misumi, J.K. Moore, A. Ridgwell, E. Sherman, and others. 2016. How well do global ocean biogeochemistry models simulate dissolved iron distributions? Global Biogeochemical Cycles 30(2):149-174, https://doi.org/10.1002/2015GB005289.

Turner, D.R., E.P. Achterberg, C.-T.A. Chen,

S.L. Clegg, V. Hatje, M.T. Maldonado, S.G. Sander, C.M.G. van den Berg, and M. Wells. 2016. Towards a quality-controlled and accessible Pitzer Model for seawater and related systems. Frontiers in Marine Science, https://doi.org/10.3389/fmars.2016.00139.

Turner, D.R., and K.A. Hunter. 2001. The

Biogeochemistry of Iron in Seawater. John Wiley and Sons, $410 \mathrm{pp}$.

Wolff, T. 2010. The Birth and First Years of the Scientific Committee on Oceanic Research (SCOR). Scientific Committee on Oceanic Research, Baltimore, Maryland, USA.

\section{ACKNOWLEDGMENTS}

SCOR is supported by 31 national SCOR committees, several hundred scientists who volunteer their time to support SCOR work, national funding agencies such as the US National Science Foundation that support SCOR working groups, many national institutions and agencies that support international project offices for SCOR activities, and several charitable foundations. The International Atomic Energy Agency is grateful to the government of the Principality of Monaco for the support provided to its Environment Laboratories.

\section{AUTHORS}

Edward R. Urban Jr. (ed.urban@scor-int.org) was Executive Director of the Scientific Committee on Oceanic Research, currently based at University of Delaware, Newark, DE, USA, from 2000 to 2020. Andrew R. Bowie is Professor, Institute for Marine and Antarctic Studies, University of Tasmania, Hobart, Australia. Philip W. Boyd is Professor, Institute for Marine and Antarctic Studies, University of Tasmania, Hobart, Australia. Kristen N. Buck is Associate Professor, College of Marine Science, University of South Florida, Tampa, FL, USA. Maeve C. Lohan is Professor, National Oceanography Centre, Southampton, UK. Sylvia G. Sander is Section Head, IAEA Nuclear Applications Marine Environmental Studies Laboratory, Monaco. Reiner Schlitzer is Professor, Alfred Wegener Institute, Helmholtz Centre for Polar and Marine Research, Bremerhaven, Germany. Alessandro Tagliabue is Professor, University of Liverpool, Liverpool, UK. David Turner is Professor Emeritus, Department of Marine Sciences, University of Gothenburg, Gothenburg, Sweden.

\section{ARTICLE CITATION}

Urban, E.R. Jr., A.R. Bowie, P.W. Boyd, K.N. Buck, M.C. Lohan, S.G. Sander, R. Schlitzer, A. Tagliabue, and D. Turner. 2020. The importance of bottom-up approaches to international cooperation in ocean science: The iron story. Oceanography 33(1):11-15, https://doi.org/10.5670/oceanog.2020.109.

\section{COPYRIGHT \& USAGE}

This is an open access article made available under the terms of the Creative Commons Attribution 4.0 International License (https://creativecommons.org/ licenses/by/4.0/), which permits use, sharing, adaptation, distribution, and reproduction in any medium or format as long as users cite the materials appropriately, provide a link to the Creative Commons license, and indicate the changes that were made to the original content. 